\title{
A escrita alfabética grega: uma invenção da pólis? A contribuição da arqueologia
}

\author{
HAIGANUCH SARIAN \\ Museu de Arqueologia e Etnologia \\ Universidade de São Paulo
}

\begin{abstract}
RESUMO: Com a desagregação dos palácios micênicos no final do Bronze Recente (1250-1100 a.C.) desapareceram a um só tempo a escrita Linear B que conotava o grego micênico e as estruturas palaciais, fato explicado pela utilização do silabário micênico apenas no quadro da administração oficial dos palácios. Entretanto, esta escrita linear, de origem cretense, sobrevive em Chipre, levada pelos colonos aqueus ou mesmo, anteriormente, pelos minóicos, num momento de profundos contatos em território sírio agrupando cipriotas e componentes originários da ilha da Creta. Surpreendentemente, Chipre conservou registros da escrita linear cretense, sobretudo a partir do séc. IX a.C. até o séc. III a.C., tendo servido para conotar tanto a língua local - o eteocipriota - quanto o grego cipriota. Na própria Grécia, durante três séculos parece terse desconhecido qualquer forma de escrita e a ocupação humana limita-se a algumas poucas aglomerações. Quando a escrita reaparece, não se trata mais de silabário cretense, mas de uma escrita alfabética "inventada" pelos gregos a partir do alfabeto fenício, conhecido e divulgado desde os sécs. XI e X, época do início da expansão dos fenícios pelo Mediterrâneo. Trata-se, sem dúvida alguma, de uma das maiores contribuições culturais para o mundo ocidental, pois na origem desta "invenção" do alfabeto grego situa-se a família dos alfabetos ocidentais - de início o etrusco e o latino, e a partir dai os que dominam o Ocidente. Minhas reflexões sobre o surgimento da escrita alfabética grega no quadro da polis implica questionar quando, onde e para quê os gregos inventaram o seu alfabeto. A data e a região estão associadas e devem ser analisadas conjuntamente. Os dados arqueológicos, lingüísticos e históricos apontam para o séc. IX a.C. a adaptação grega do alfabeto fenício e o seu uso primitivo teria sido o da administração comercial, desenvolvida entre os gregos, cipriotas e fenícios no litoral norte da Siro-Fenícia. No tocante à articulação entre a invenção da escrita alfabética grega e a origem da pólis, algumas questões serão aprofundadas.
\end{abstract}

PALAVRAS-CHAVE: Grécia; escrita; alfabeto; pólis; arqueologia clássica; história antiga. 


\section{Introdução}

Os historiadores modernos denominam "Renascimento Grego" o período situado entre meados do séc. IX e meados do séc. VIII a.C. e incluem nesta faixa de tempo as grandes "invenções" da época Geométrica: surgimento da escrita alfabética, colonização, os poemas homéricos, a arte figurativa, as primeiras póleis. Essas manifestações do espírito grego não têm, todas, a mesma cronologia e nem sempre estão interligadas. E elas prendemse às questões histórico-culturais características da Idade do Ferro em seus começos (1050900) - fase Protogeométrica seguida de uma fase mais desenvolvida (950-700) - a fase Geométrica.

Ao final do Bronze Recente, segue-se em Chipre um período de dois séculos, pouco conhecido, como na Grécia, mas em que continuaram as tradições da civilização aquéia comprovadas por sobrevivências a partir do séc. XI a.C. Nesta época e a seguir, Chipre revela um componente de tradição micênica associado a elementos locais eteocipriotas. Perdura o silabário de origem cretense, servindo agora para transcrever a língua grega, enriquecida pela passagem constante de gregos a caminho do Levante, onde fundaram importantes entrepostos em Tarso e Al Mina.

A ausência de ruptura, que parece ter-se imposto à cultura grega continental pela vinda dos dórios, favoreceu o caráter conservador da cultura cipriota ao longo dos períodos Geométrico e Arcaico, transparente na religião, nos costumes funerários, nas tendências artísticas e na língua onde se observa nítida sobrevivência micênica, fundamento da cultura cipriota do alto arcaísmo, ainda que permeável em alguns aspectos às influências como, por exemplo, fenícia, assíria e egípcia.

Esta intermediação constante exercida por Chipre entre a Grécia e o Oriente possibilitou aos cipriotas o desempenho de relevante papel nos contatos havidos entre gregos e levantinos sobretudo no momento em que surgiu o alfabeto grego, inspirado do fenício.

Com a desagregação dos palácios micênicos no final do Bronze Recente (12501100 a.C.) desapareceram a um só tempo a escrita Linear B que conotava o grego micênico e as estruturas palaciais, fato explicado pela utilização do silabário micênico apenas no quadro da administração oficial dos palácios. Entretanto, esta escrita linear, de origem cretense, sobrevive em Chipre, levada pelos colonos aqueus ou mesmo, anteriormente, pelos minóicos, num momento de profundos contatos em território sírio agrupando cipriotas e componentes originários da ilha de Creta. Surpreendentemente Chipre conservou registros da escrita linear cretense, sobretudo a partir do séc. XI a.C. até o séc. III a.C., tendo servido para conotar tanto a língua local - o eteocipriota - quanto o grego cipriota.

Na própria Grécia, durante três séculos parece ter-se desconhecido qualquer forma de escrita e a ocupação humana limita-se a algumas poucas aglomerações. Quando a escrita reaparece, não se trata mais de silabário cretense, mas de uma escrita alfabética "inventada" pelos gregos a partir do alfabeto fenício, conhecido e divulgado desde os sécs. XI e X, época do início da expansão dos fenícios pelo Mediterrâneo. Antes disso, vale lembrar as inscrições proto-sinaíticas: os primeiros vestígios de uma escrita alfabética são encontrados em inscrições proto-sinaíticas (1600 a.C.) e atestam que ela já se anunciara antes que os fenícios a tivessem sistematizado e divulgado. Com efeito, nos períodos de Médio e Novo Império (2040-1550 a.C. / 1550-1070 a.C.) os egípcios vinham a Serabit el Khadim, na península do Sinai, a fim de explorar as minas de turquesa, uma pedra preciosa que representava um importante papel na ideologia real faraônica. Além de inúmeras inscrições egíp- 
cias, foram descobertas nesta localidade umas trinta inscrições em escrita pictográfica, denominadas de proto-sinaíticas, que registram uma língua semítica ocidental aparentada àquelas que eram faladas no Levante durante a segunda metade do II milênio a.C. e do mesmo grupo que o fenício. Estas inscrições poderiam ter sido gravadas por membros de uma expedição vinda do Levante para a exploração da turquesa por volta de 1600 a.C.

Ainda que esta escrita pictográfica apresente uma vaga semelhança com os sinais egípcios, ela registra uma modalidade de alfabeto que teve, desde o II milênio a.C., um sucesso inesperado, destacando-se sua influência nos alfabetos de Ugarit e da Fenícia, e deste alfabeto, a "invenção" grega. Trata-se, sem dúvida alguma, de uma das maiores contribuições culturais para o mundo ocidental, pois na origem desta "invenção" do alfabeto grego situa-se a família dos alfabetos ocidentais - de início o etrusco e o latino, e a partir daí os que dominam o Ocidente. Convém, entretanto, nuançar a palavra "invenção": na verdade, quando se fala em "invenção" do alfabeto grego entende-se por uma "adaptação" do alfabeto fenício às exigências da língua grega e, em particular, a adoção de cinco sinais determinados, que se encontravam no alfabeto fenício, para exprimir as cinco vogais que terão largo uso na língua grega.

\section{Arqueologia e história}

Minhas reflexões sobre o surgimento da escrita alfabética grega no quadro do surgimento da pólis implica em questionar quando, onde e para quê os gregos inventaram o seu alfabeto. A data e a região estão associadas e devem ser analisadas conjuntamente. Os dados arqueológicos, lingüísticos e históricos apontam para o séc. IX a.C. a adaptação grega do alfabeto fenício e o seu uso primitivo teria sido o da administração comercial, desenvolvida entre gregos, cipriotas e fenícios no litoral norte da Siro-Fenícia. No tocante à articulação entre a invenção da escrita alfabética grega e a origem da pólis, algumas questões serão aprofundadas.

Antes de apresentar as mais antigas inscrições alfabéticas gregas conhecidas, vale lembrar que os autores antigos, mais de uma vez, trataram do problema da origem do alfabeto. Na maioria destas fontes ressalta-se um etnocentrismo exagerado e característico: ou bem foi o engenhoso herói argivo Palamedes que segundo o poeta Estesícoro, teria inventado as letras gregas (escólio a Dioniso trácio), ou bem teria sido Prometeu o seu inventor (Ésq. Prom., 460).

O texto mais importante é o de Heródoto (V, 58-61), segundo o qual, Cadmo, rei dos fenícios, havia transmitido o alfabeto aos gregos quando chegou à Beócia; os gregos

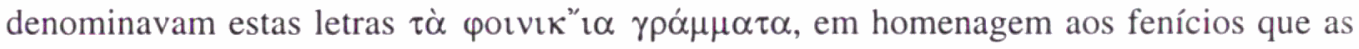
haviam inventado. Cadmo é uma figura lendária dos tempos micênicos e, portanto, desta passagem de Heródoto fica apenas a informação historicamente comprovada de que o alfabeto grego é de origem fenícia.

As primeiras inscrições conhecidas do alfabeto grego situam-se no séc. VIII a.C. uma é da primeira metade do séc. VIII, as outras de sua segunda metade - e provêm de diferentes regiões:

1) Cinco letras gregas encontradas nas escavações de Osteria dell'Osa - Gabies, na Itália (região central do Tirreno): são as mais antigas e datam da primeira metade do séc. VIII a.C. mas elas são ilegíveis (fig. 1). 
2) Atenas: inscrição no ombro de uma enócoa do G R I b (740-725 a.C.), fabricada na oficina do Dípylon. Como em todas as inscrições fenícias e gregas arcaicas, as letras se lêem da direita para a esquerda e algumas delas são já bastante evoluídas com relação às fenícias; outro dado importante para atestar o distanciamento entre os dois alfabetos é o registro de c uma das letras suplementares que os gregos acrescentaram ao repertório fenício original. Esta enócoa era certamente o prêmio destinado ao vencedor: "àquele que dentre todos os dançarinos dançar com mais graça", tal é o verso completo em hexâmetro anunciando uma competição (figs. 2 e 3 ).

3) Rodes: inscrição num fragmento de taça (kylix) de meados do séc. VIII, indicando o proprietário. Na frase "eu sou a kylix de Qoragos", temos igualmente formas evoluídas, a inclusão do $\chi$ (como na inscrição anterior) e a gutural qoppa (q) antes do o e do $v$ característica da escrita grega em seus inícios (fig. 3).

4) Eubéia: há várias inscrições anteriores a 710 a.C. Os exemplares mais importantes foram encontrados na colônia eubóica de Pitecussa (atual ilha de Ischia, na Itália). A mais notável, em taça (kotyle) conhecida como "a taça de Nestor", compõe-se de três linhas em hexâmetro: "eu sou a taça de Nestor, quem beber desta taça, logo o tomará o desejo de Afrodite de bela coroa". Esta taça, importada de Rodes, foi encontrada numa sepultura e o alfabeto nela registrado é eubóico, sendo datado, através do contexto arqueológico, de 740-725 a.C (fig. 3).

Em todas estas inscrições as letras já apresentam formas muito evoluídas em relação ao alfabeto fenício. O exemplar de Pitecussa é bastante revelador nas formas do alfa (de pé e não deitado), no surgimento do phi e na forma do sigma (५). Ora, os colonos gregos provenientes da Eubéia ocuparam Pitecussa na primeira metade do séc. VIII (provavelmente em 775 a.C.) e levaram o alfabeto consigo. Isto se confirma também em um pequeno fragmento inscrito (fig. 3) descoberto em Ischia, onde se lê um alfa deitado e um pi. Este alfa deitado é de tipo mais arcaico do que o alfa de pé da "taça de Nestor". Logo, esta minúscula inscrição data da primeira metade do séc. VIII. Se, pois, o alfabeto grego era conhecido em Pitecussa/Ischia na primeira metade do séc. VIII, é preciso admitir que os gregos da Eubéia o conhecessem pelo menos no final do séc. IX, se não mesmo antes. Tal cronologia para o surgimento do alfabeto grego encontra fundamentação epigráfica na Etrúria e no Lácio, regiões de intenso contato com os gregos. Apesar de a maior parte das inscrições etruscas, em seus inícios, datarem do séc. VIII e VII a.C., e as latinas do séc. VII e VI a.C., descobertas de 1989 no sítio arqueológico de Gabies nas proximidades de Roma revelaram uma inscrição latina já do último quarto do séc. VII a.C. (fig. 4). Ora, uma inscrição latina com esta data e as inscrições gregas da primeira metade do séc. VIII a.C. obrigam-nos a recuar a data da origem do alfabeto grego, situando-a no séc. IX a.C.

A data provável da adaptação do alfabeto fenício ao alfabeto grego - séc. IX a.C. conduz-nos a indagar sobre o local deste fenômeno. Convém lembrar aqui as observações de L. H. Jeffery (1990) de que o local do surgimento do alfabeto grego seria bem freqüentado pelo comércio em uma comunidade bilíngüe, com fenícios e gregos. Ora, os fenícios tiveram contato com os gregos em várias regiões do Mediterrâneo, desde o séc. XI a.C. Mas é sobretudo no séc. IX que estes contatos se multiplicam na própria costa siro-fenícia, prin- 
cipalmente na parte N compreendendo os sítios de Al-Mina, Ras-el-Bassit, Tell Sukas, mas também em direção ao S, na região de Sídon, na localidade de Tamburit (fig. 5). Nesses sítios a importação da cerâmica grega e cipriota é maciça, sobretudo cerâmica da Eubéia, incluindo ainda vasos cicládicos e um importante exemplar argivo.

Al-Mina, ao N, foi, desde a sua descoberta nos anos 30, uma localidade apontada pelos estudiosos como tendo exercido papel relevante na origem do alfabeto grego. Atualmente, os dados arqueológicos resultantes dessas escavações, de interpretação muito controvertida, afastam tal predomínio, sobretudo se atentarmos para o fato de que, pelo estudo da cerâmica, é impossível recuar a mais antiga ocupação de Al Mina a um período anterior a meados do séc. VIII a.C. Em Ras-el-Bassit, possivelmente a Posideion mencionada por Heródoto (III, 91), uma taça cicládica (figs. 6-7) datada de 850-825 a.C. lança novas luzes para a questão dos contatos entre gregos e levantinos já desde o séc. IX. O tipo de decoração desta taça - grupos de semicírculos concêntricos suspensos na borda do recipiente - caracteriza uma categoria cerâmica muito frequiente nas Cíclades do N (Tinos, Andros, Kea), em Lefkandi, na Eubéia, e além da descoberta de Ras-el-Bassit, dispomos de exemplares idênticos em outras localidades do Mediterrâneo oriental, como em Chipre (Amatonte, Salamina), em Tarso (Cilícia) e Tiro.

Porém ao longo convívio entre os gregos e fenícios no Levante há a acrescentar o papel determinante de Chipre, cuja cerâmica é largamente atestada no litoral siro-fenício desde o séc. IX a.C. Ora, a importância de Chipre no processo de formação do alfabeto grego a partir do alfabeto fenício apoia-se exatamente na sobrevivência do silabário micênico nesta ilha, para conotar seja o grego local seja a língua autóctone, o eteocipriota. Sabemos que a escrita fenícia é unicamente consonântica, mas os gregos, ao adaptá-la à sua língua, inspiraram-se do silabário cretense remanescente no silabário cipriota - onde, precisamente, subsistem, a partir do modelo micênico, as cinco vogais introduzidas no alfabeto grego.

De modo que, a meu ver, a condição adequada para favorecer o surgimento do alfabeto grego é não apenas a conjunção do elemento grego e fenício no Levante, mas sim o elemento determinante, a presença de cipriotas.

Nesta ordem de idéias, a localidade de Tamburit (fig. 5), na região de Sídon, ao S do litoral levantino, oferece, através de seus achados arqueológicos, importante degrau nessa reconstituição histórica: numa tumba da Idade do Ferro, foram descobertas em associação (figs. 8-9) uma píxide de estilo geométrico (possivelmente argiva) - de 850-825 a.C., e uma ânfora característica da produção local de inspiração cipriota (850-800 a.C.); a particularidade desta ânfora é uma epígrafe fenícia ('qm) identificada ao topônimo 'Aqmata (indicador da origem geográfica do conteúdo primitivo da ânfora).

De modo que, embora seja difícil determinar a localidade exata onde os gregos, fenícios e cipriotas tenham convivido por algum tempo, favorecendo o empréstimo que os gregos fizeram do alfabeto fenício e do silabário cipriota, as evidências arqueológicas, lingüísticas e histórico-culturais apontam para o litoral do Levante e nos conduzem a examinar questão de tal complexidade em termos regionais e não locais. A região (fig. 5) que vai de Tarso, ao N, até Tiro, ao S, mereceria ser analisada mais longamente e em profundidade. Ora, esse litoral é uma região predestinada na história da invenção do alfabeto. Foram os canaanitas de Ugarit que criaram o alfabeto cuneiforme no séc. XIV a.C., com trinta letras consonânticas, das quais vinte e duas foram adaptadas ao alfabeto fenício nos sécs. XI-X a.C.

E nesta região do Levante, predestinada na história da invenção do alfabeto grego, há que ressaltar o relevante papel exercido por Chipre. 
Qual teria sido o uso inicial da escrita, ou melhor, para quê se inventou o alfabeto grego? Segundo alguns autores, sobretudo K. Robb (1978) e A. Shnapp Gourbeillon (1982) a origem da escrita alfabética grega é poética, uma vez que a natureza das primeiras inscrições está intimamente relacionada com a poesia. Nesse contexto, devo mencionar a questão relativa a Homero e à escrita, isto é, à "alfabetização" de Homero. Os poemas homéricos foram compostos em ambiente da Jônia asiática, entre o fim do séc. IX e o fim do séc. VIII a.C. Pressuporiam o uso da escrita? Tal é a questão eternamente debatida entre os homeristas que discorrem sobre a passagem da oralidade à escrita no tocante à Ilíada e à Odisséia. No estágio atual do nosso conhecimento, por mais importância que se queira dar à força da tradição oral e à capacidade mnemônica dos aedos, não se pode negar que os poemas homéricos tenham sido fixados pelo menos em algumas de suas partes, por escrito. E esta escrita foi necessariamente a escrita alfabética que na segunda metade do séc. VIII a.C. já havia atingido um momento de evolução suficiente para a conotação métrica, como testemunham as inscrições da enócoa do Dípylon e da "taça de Nestor" acima referidas. As condições histórico-culturais por outro lado, apontam para o grande fenômeno da difusão dos poemas homéricos no mundo grego a partir de meados do séc. VIII a.C. A "taça de Nestor" com a inscrição em hexâmetro memoriza sem dúvida a célebre passagem da Ilíada XI, 632-637 em que se descreve a taça do herói aqueu, o velho Nestor; a enócoa do Dípylon é um prêmio a um vencedor em concurso de dança e sua inscrição é também em hexâmetro.

A apropriação da escrita pela poesia deu-se numa fase evoluída das letras alfabéticas. Qual teria sido então o uso inicial da escrita grega?. Uma conjunção de fatores parece indicar que o uso primitivo do alfabeto grego foi sem dúvida o da administração comercial. Os mercadores gregos, em contato com seus homólogos fenícios, teriam aprendido deles a técnica alfabética que lhes permitiu organizar melhor os mecanismos da troca. Esta prática nos remete às primeiras utilizações da escrita na Grécia, a Linear B em contexto micênico, e bem antes, no Bronze Antigo do Egeu, um sistema de notação simbólica, os pictogramas, que tornavam possível a organização da economia, para cujo sistema temos ainda o paralelo da Mesopotâmia com seus primeiros tabletes cuneiformes datados do quarto milênio a.C. e que exprimiam textos de contabilidade. Os estudos recentes de Jack Goody, antropólogo inglês, orientam-se nesta linha de reflexão ou para demonstrar que a escrita em seus começos serve muito mais para organizar listas de palavras do que para conotar a continuidade de um discurso, ou para apoiar, em conseqüência dessa primeira especialização da escrita, o seu uso mercantil. Tal é também a direção de Mario Lombardo que em artigo de 1988 não deixa de apontar o seguinte: "Com efeito, a observar as fases iniciais da experiência escritural grega, o domínio das transações econômicas parece ter uma importância primordial, na medida em que se lhe atribui com muita freqüência um papel original e fundamental na leitura dos processos de introdução e de difusão da escrita alfabética, que teria encontrado aí seu campo prioritário e privilegiado de utilização e de funcionalidade" (Detienne, 1988, p. 161). Tal realidade não passou desapercebida pelos gregos, a concluir de uma passagem de Aristóteles (Política VIII, 3, 1388 a): ressaltando a utilidade da escrita, dos grámmata, em vários campos de atividade, menciona logo de início: krematismós e oikonomía, vale dizer "os negócios" e a "administração do patrimônio".

Perdura a questão da falta de inscrições de caráter econômico nos começos da utilização do alfabeto na Grécia. Esta ausência de testemunhos tanto pode se explicar pelo acaso das descobertas arqueológicas quanto pelo provável uso de materiais perecíveis para suporte dessas primeiras inscrições. 
A escrita alfabética grega é anterior, posterior ou contemporânea às póleis? Como vimos, ela surge no séc. IX a.C., pelo menos. Para entender a interligação entre escrita e pólis é necessário recorrer ao que se conhece hoje, pela arqueologia, no tocante aos assentamentos na Grécia dos períodos Protogeométrico e Geométrico.

Há, na verdade, poucos habitats característicos durante estes períodos. Na maior parte dos sítios, possuímos vestígios de algumas casas e sobretudo necrópoles ou agrupamentos de sepulturas, como é o caso de Atenas, Argos, Iolcos, Iálisos, Cnossos e, sobretudo, Lefkandi, na Eubéia. Mais recentemente, descobertas arqueológicas na ilha de Andros, no sítio de Zágora, revelaram uma importante ocupação situada cronologicamente entre 850 e 750 a.C. O exemplo a destacar é o de Lefkandi, onde se encontrou uma ocupação contínua da fase final da Idade do Bronze (sub-micênico, primeira metade do séc. XI a.C.) até o Geométrico Recente (segunda metade do séc. VIII a.C.), passando por todas as fases intermediárias. A cultura material característica de Lefkandi revela muito mais do que uma simples aglomeração. Basta lembrar um edifício em ábside, cujas dimensões se aproximam de $50 \mathrm{~m} \times 10 \mathrm{~m}$ e datado do séc. X a.C. Este edifício foi identificado de início a um herôon, isto é um santuário de morto heroicizado: a descoberta de uma sepultura de um casal humano e de traços de sacrifícios de quatro cavalos orientavam nesse sentido. A. MazarakisAinian (Sarian, 1989) interpreta-o como a residência do basileus de Lefkandi, e os vestígios funerários seriam os do casal real. Qualquer que seja a interpretação funcional deste edifício, herôon ou residência real, o culto funerário nele presente aponta para um edifício excepcional para a época e destaca Lefkandi na Eubéia como um assentamento suficientemente aparelhado para a aventura do comércio e da colonização. A par da situação privilegiada de Lefkandi, temos ainda a cidade de Erétria, também na ilha de Eubéia, cuja ocupação é um pouco posterior, final do séc. IX, mas igualmente importante. De modo que, dos sítios gregos de inícios da Idade do Ferro, tiveram um papel preponderante Lefkandi e Erétria na Eubéia, Zágora, na ilha cicládica de Andros. Entende-se bem que a cerâmica eubóica e cicládica tenham exercido especial função nos contatos e trocas com o litoral levantino e, no caso da Eubéia, também com o Ocidente grego (vale lembrar a colonização de Pitecussa). Todos estes assentamentos, cuja cultura material caracteriza cidades em pleno desenvolvimento, não podem entretanto ser identificados como cidades-estados, isto é, como póleis. Neste contexto, a escrita alfabética é anterior ao surgimento da pólis e foi uma invenção originada da atividade mercantil e artesanal.

Não se trata de uma especificidade grega no tocante ao alfabeto, como vimos acima. Todo modelo teórico oferecido pela Antropologia orienta para uma necessidade de escrita sempre que uma sociedade se organiza no sentido da hierarquização e do controle do poder. As reflexões de C. Lévi-Strauss sobre a escrita são determinantes a esse respeito: “...o único fenômeno que parece estar ligado, sempre e por toda parte, ao surgimento da escrita, não só no Mediterrâneo oriental, mas também na China proto-histórica, e mesmo nessas regiões da América onde surgiram esboços de escrita antes da conquista, é a formação de sociedades hierarquizadas, de sociedades compostas de senhores e de escravos, de sociedades utilizando uma certa parte de sua população para trabalhar em proveito da outra parte" (Charbounier, 1961, 32-33)

Só haverá uma utilização poética da escrita em um segundo momento. A escrita, a serviço da cidade, com função pública e política, só aparecerá bem mais tarde, na segunda metade do séc. VII a.C., quando começam a surgir os códigos de leis. Basta citar aqui, para concluir, o fragmento de uma grande inscrição em pedra da cidade de Dreros, em Creta (fig. 
10), desse período. Trata-se do mais antigo exemplo conhecido de escrita alfabética grega a serviço da pólis, mas estamos agora há quase dois séculos da sua "invenção".

\section{Referências bibliográficas}

ANDRONICOS, M. "The Mycenaean and the Greek script". In: Atti del Congresso (1, 1967, Roma). Roma, 1968. p.500-503.

BAURAIN, C. Chypre et la Méditerranée Orientale au Bronze Récent. Synthèse historique. Athènes: École Française d'Athènes; Paris: De Boccard, 1984 (Études Chypriotes, 6).

. Les Grecs et la Méditerranée Orientale. Paris: Presses Universitaires de France, 1997 (Coll. Nouvelle Clio).

BAURAIN, C., BONNET, C., KRINGS, V. (Éd.). Phoinikeia Grammata. Lire et écrire en Méditerranée. Namur: Société des Études Classiques, 1991.

BIETTI SESTIERI, A. M. The Iron Age community of Osteria dell'Osa. Cambridge: Cambridge University Press, 1992. (New Studies in Archaeology).

BIETTI SESTIERI, A. M., De SANTIS, A., LA REGNA, A. Elementi di tipo cultuale e doni personali nella Necropoli Laziale di Osteria Dell'Osa. Scienze dell'Antichità. Storia, Archeologia, Antropologia, Roma, v. 3-4, p. 65-88, 1989-1990 (publicado em 1991).

BOARDMAN, J. The Greeks overseas. London: Thames and Hudson, 1973. (1. ed. 1964).

Al Mina and History. Oxford Journal of Archaeology, v. 9, p. 169-190, 1990.

BURKERT, W. The orientalizing revolution. near eastern influence on Greek culture in the early Archaic Age. Cambridge, London: Harvard University Press, 1992.

CAMBitoglou, A., ZAGORA, Andros. A settlement of the Geometric Period. Archaeology, v. 23, p. 303-309, 1970.

CARPENTER, R. The alphabet in Italy. Supplement to American Journal of Archaeology, v. 49 , p. $452-464,1945$.

CHARBOUNIER, G. Entretiens avec Claude Lévi-Strauss. Paris: Plon/Julliard, 1961.

COLDSTREAM, J. H. Geometric Greece. London: Methuen, 1977.

COLONNA, G. Graeco more bibere: l'Inscrizione della Tomba 115 dell'Osteria dell'Osa. In: Archaeologia Laziale, 3. Terzo Incontro di Studio del Comitato per l'Archeologia Laziale. Roma: [s.n.t.], 1980. p. 51-55. (Quaderni del Centro di Studio per l'Archeologia Etrusco-Italica, 4).

COULET, C. Communiquer en Grèce ancienne. Paris: Les Belles Lettres, 1996.

COURBIN, P. Une assiette cycladique à Ras el Bassit. Archéologie au Levant. Recueil R. Saidah. Maison de l'Orient Ancien, 1984. p.193-204.

DELAVANT, B. Une des plus grandes inventions de l'humanité, l'écriture phénicienne. Archeologia, v. 20, p. 34-39, 1968.

DETIENNE, M. (dir.). Les Savoirs de l'Écriture en Grèce Ancienne. S.1.: Presses Universitaires de Lille, 1988. (Collection Cahiers de Philologie. Série Apparat Critique, 14). 
DUHOUX, Y. Les étéocretois et l'origine de l'alphabet grec. L'Antiquité Classique, p. 287294, 1981.

GODARD, L. Le pouvoir de l'écrit: aux pays des premières écritures. Paris: Armand Colin, 1990.

GOODY, J. La logique de l'écriture. Aux origines des sociétés humaines. Paris: Armand Colin, 1986.

. The interface between the written and the oral. Cambridge: Cambridge University Press, 1993. 1. ed. 1987).

La raison graphique. La domestication de la pensée sauvage. Paris: Les Éd. de Minuit, 1979 (ed. Inglesa, 1977).

GOOLD, G. P. Homer and the Alphabet. Transactions and Proceedings of the American Philological Association, v. 91, p. 272-291, 1960.

GUARDUCCI, M. Epigrafia Greca I. Roma: Istituto Poligrafico Stato, 1967.

L'epigrafia greca dall'origini al Tardo Impero. Roma: Libreria dello Stato, 1987.

HANSEN, M. H. Polis and city-state. An ancient concept and its modern equivalent. Copenhagen: The Royal Danish Academy of Sciences and Letters, 1998.

HAVELOCK, E. A. A revolução da escrita na Grécia e suas conseqüências culturais. São Paulo: Editora UNESP e Paz e Terra, 1996.

IMMERWAHR, H. R. Attic script. A survey. Oxford: Clarendon Press, 1990.

IRIGOIN, J. Les grecs et l'écriture. Quelques jalons historiques. Corps Écrits 1, "L'Écriture". Paris: PUF, 1982. p. 32-38.

JEFFERY, L. H. The local scripts of archaic Greece. Oxford: Clarendon Press, 1990. (Revised edition with a Supplement by A. W. Johnston).

KARAGEORGHIS, J. Quelques observations sur l'origine du syllabaire Chypro-Minoen. Revue Archéologique, p. 1-19, 1958.

Histoire de l'écriture chypriote. Kypriakai Spoudai, p. 43-60, 1961.

(Ed.). The history of the Greek language in Cyprus. In: Proceedings of the International Symposium sponsored by the Pierides Foundation (8-13 September: 1986: Larnaca). Nicosia, 1988.

KARAGEORGHIS, V. Chypre. Genève: Les Éditions Nagel, 1968. (Archaeologia Mundi).

Cyprus. In: BOARDMAN, J., EDUARDS, I.E.S., HAMMOND, N.G.L., SOLLBERGER, E. The Prehistory of the Balkans: and the Middle East and the Aegean World, tenth to eighth centuries B.C. Cambridge: Cambridge University Press, 1982. (The Cambridge Ancient History, second edition, vol. III, part 1). p. 511-533.

LUNDIN, A. G. Ugarit writing and the origin of the Semitic consonantal alphabet. Aula Orientalis, v. 5, p. 91-99, 1987.

MAZARAKIS-AINIAN, A. Geometric Eretria. Antike Kunst, v. 30, p. 3-24, 1987.

MITFORD, T. B., MASSON, O. The Cypriot syllabary. In: BOARDMAN, J., HAMMOND, N. G. L. The expansion of the Greek world, eighth to sixth centuries B.C. Cambridge: Cambridge University Press, 1982. (The Cambridge Ancient History, second edition, vol. III, part 3). p. 71-82. 
MORRIS, I. The early polis as city and state. In: RICH, J., WALLACE-HADRILL, A. (Eds.). City and Country in the Ancient World. London: Routledge, 1991. p. 24-57.

PERUZZI, E. Cultura grega a Gabii nel Secolo VIII. La Parola del Passato, v. 47, p. 459-568, 1992.

POWELL, B. B. Homer and the Origin of the Greek Alphabet. Cambridge: Cambridge University Press, 1991.

ROBB, K. Literacy and paideia in ancient Greece. Oxford: Oxford University Press, 1994.

ROCCHI, M. Lineare B e alfabeto nel mito di Palamedes. In: La Transizione dal Miceneo all' Alto Arcaismo Dal Palazzo alla Città. Atti del Convegno Internazionale. Roma, 14-19 marzo 1988. Roma: Consiglio Nazionale delle Ricerche, 1991. p. 551-561.

SAIDAH, R. Une tombe de l'Âge du Fer à Tambourit (Région de Sidon). Berytus. Archaeological Studies, v. 25, p. 135-161, 1977.

SARIAN, H. La civilisation mycénienne: continuités et ruptures. In: TREUIL et alii. Les civilisations égéennes: le Néolithique et l'Âge du Bronze de l'Anatolie aux Balkans. Paris: Presses Universitaires de France, 1989. p. 585-593 (Coll. Nouvelle Clio).

SCHNAPP-GOURBEILLON, A. Naissance de l'écriture et fonction poétique en Grèce Archaïque: quelques points de repère. Annales. Économie. Religion. Société, v. 37, p. 714-723, 1982.

SNODGRASS, A. M. Archaeology and the rise of the Greek state. Cambridge: Cambridge University Press, 1977.

Archaic Greece. The Age of Experiment. Berkeley, Los Angeles: University of California Press, 1980.

SNODGRASS, A. M. The rise of the Polis: the archaeological evidence. In: HANSEN, M. H. (Ed.). The ancient Greek city-state. Copenhaguen: Royal Danish Academy of Sciences and Letters, 1993. p. 30-40.

STARCKY, J., BORDREUIL, P. Les premières inscriptions alphabétiques phéniciennes. Archeologia, v. 20, p. 102-106, 1968.

. L'invention de l'alphabet. Les Dossiers de l'Archeologie, v. 12, p. 91-101, 1975.

TEIXIDOR, J. L'inscription d'Ahiran à Nouveau. Syria, v. 64, p. 137-140, 1987.

THOMAS, R. Literacy and orality in ancient Greece. Cambridge: Cambridge University Press, 1992.

ULLMAN, B. L. Ancient writing and its influence. Toronto: University of Toronto Press, 1989.

WHITLEY, J. Literacy and law-making. The case of Archaic Crete. In: FISCHER, N., VAN WEES, H. (Ed.). Archaic Greece. New approaches and new evidence. London: Gerald Duckworth \& Co. Ltd., 1998. p. 311-331.

WOODARD, R. D. Greek writing from Knossos to Homer. Oxford: Oxford University Press, 1997.

WOOLF, G., BOWMAN, A. K. Literacy and power in the Ancient World. Cambridge: Cambridge University Press, 1996. 
SARIAN, H. L'écriture alphabétique grecque: une invention de la polis? La contribution de l'archéologie. Classica, São Paulo, 11/12, p. 159-177, 1998/1999.

RÉSUMÉ: Avec la désagrégation des palais mycéniens à la fin du Bronze Récent (1250-1100 a.C.) disparaissent en même temps l'écriture Linéaire B qui notait le Grec mycénien et les structures palaciales, fait expliqué par l'usage du syllabaire mycénien seulement dans le cadre de l'administration officielle des palais. Néanmoins, cette écriture linéraire, d'origine crétoise, survit à Chypre, transmise par les colons achéens où même avant par les minoens, à une époque de contacts profonds en térritoire syrien réunissant des chypriotes et une population originaire de Crète. Chypre a conservé des régistres de l'écriture linéaire crétoise, surtout à partir du XI ${ }^{\circledR}$ siècle av. J.C. jusqu'au $\|^{\circledR}{ }^{\circledR}$ siècle av. J.C., et cette écriture a été utilisée pour noter soit la langue locale l'étéochypriote, soit le Grec chypriote. En Grèce même, pendant trois siècles on n'a connu ancune forme d'écriture et l'occupation humaine se limitait à quelques petites aglomérations. Lorsque l'écriture réapparait, il ne s'agit plus du syllabaire crétois, mais d'une écriture alphabétique "inventée" par les Grecs à partir de l'alphabet phénicien, connu et diffusé depuis les $\mathrm{XI}^{\ominus}$ et $\mathrm{X}^{\circledR}$ siècles, époque du début de l'expansion des phéniciens par toute la région Méditerranéenne. II s'agir sans doute d'une des plus importantes contributions culturelles au monde occidental, puisque à l'origine de cette "invention" de l'alphabet grec se situe la famille des alphabets occidentaux - d'abord l'Étrusque et le Latin, ensuite tous les alphabets qui dominent l'Occident. Mes réflexions sur l'origine de l'écriture alphabétique grecque dans le cadre de la polis m'amènent à poser les questions quand, où et pourquoi les Grecs ont inventé leur alphabet. La date et la région sont associées et doivent être analysés ensemble. Les données archéologiques, linguistiques et historiques indiquent le IX $X^{\ominus}$ siècle av. J.C.; l'adaptation grecque de l'alphabet phénicien et son usage primitif auraient été celui de l'administration commerciale, dévéloppée parmi les Grecs, les Chypriotes et les Phéniciens sur la côte $\mathrm{N}$ de la Syrie-Phénicie. Pour ce qui est du rapport entre l'invention de l'écriture alphabétique grecque et l'origine de la polis, quelques questions seront approfondies.

MOTS CLÉS: Grèce; écriture; alphabet; polis; archéologie classique; histoire ancienne. 


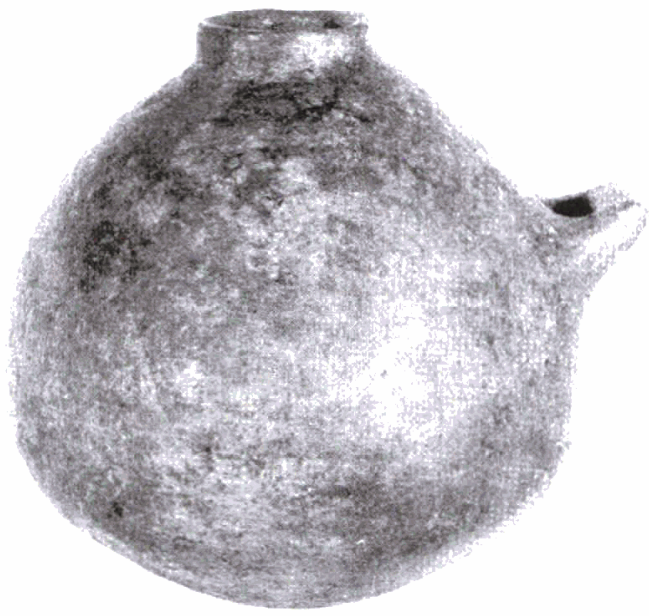

Fig. I - Inscrição grega em jarro descoberto em Osteria dell'Osa.

(Bietti Sestieri, 1992, p. 185, fig. 8, 9).
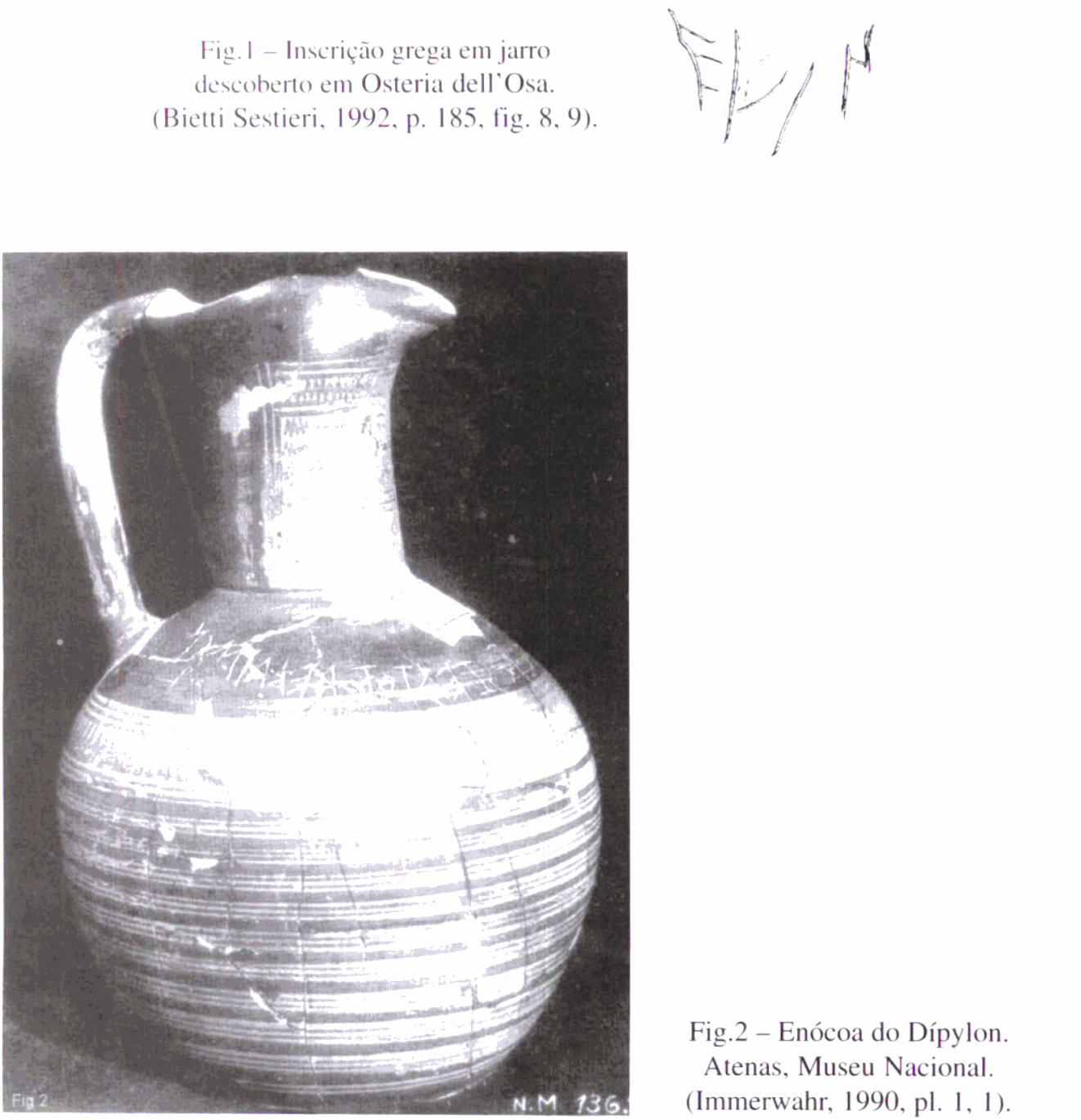

Fig.2 - Enócoa do Dípylon.

Atenas, Museu Nacional. (Immerwahr, 1990, pl. 1, 1). 

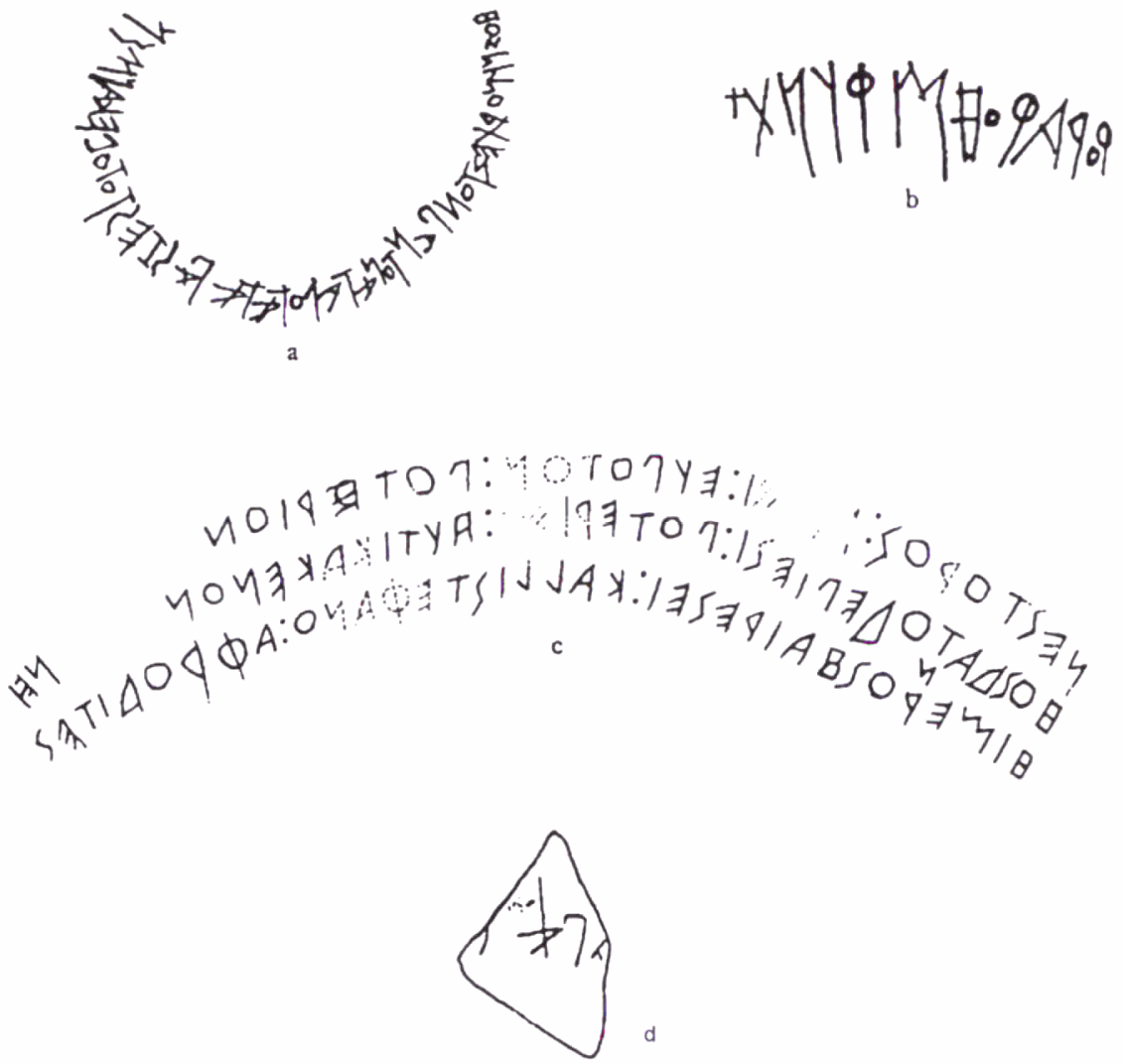

Fig. 3 - a) Inscrição ática da enócoa do Dípylon (cf. fig. 2); b) Inscrição ródia de esquifos de Qoraqos. Copenhague; c) Inscrição eubóica da taça de Nestor. Pitecussa / Ischia (Coldstream, 1997, p. 298, fig. 95); d) Inscrição de Pitecussa (Guarducci, 1967).
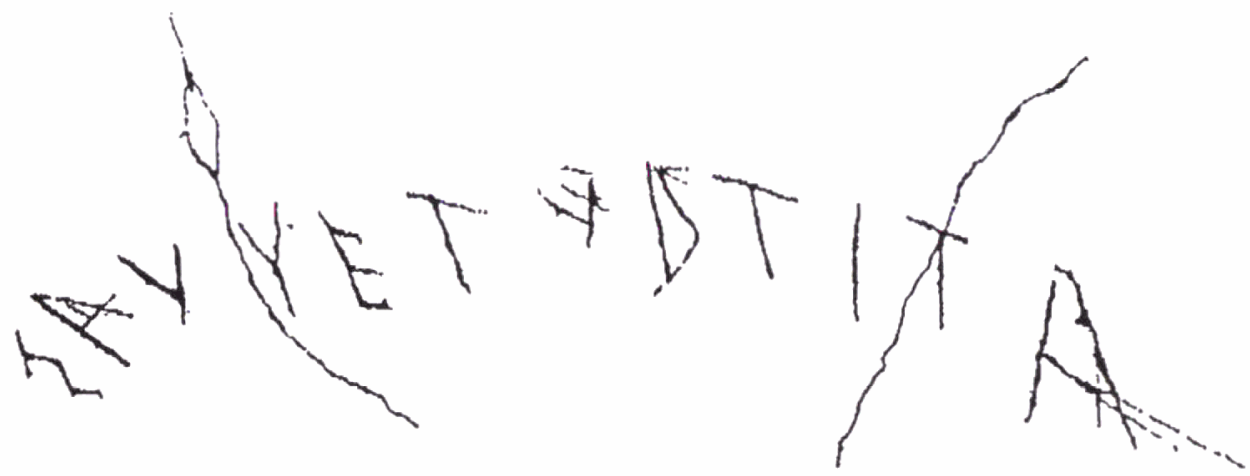

Fig. 4 - Inscrição latina de Osteria dell'Osa (necrópole de Gabies, tumba 115).

(Collona, 1980, fig. 1). 


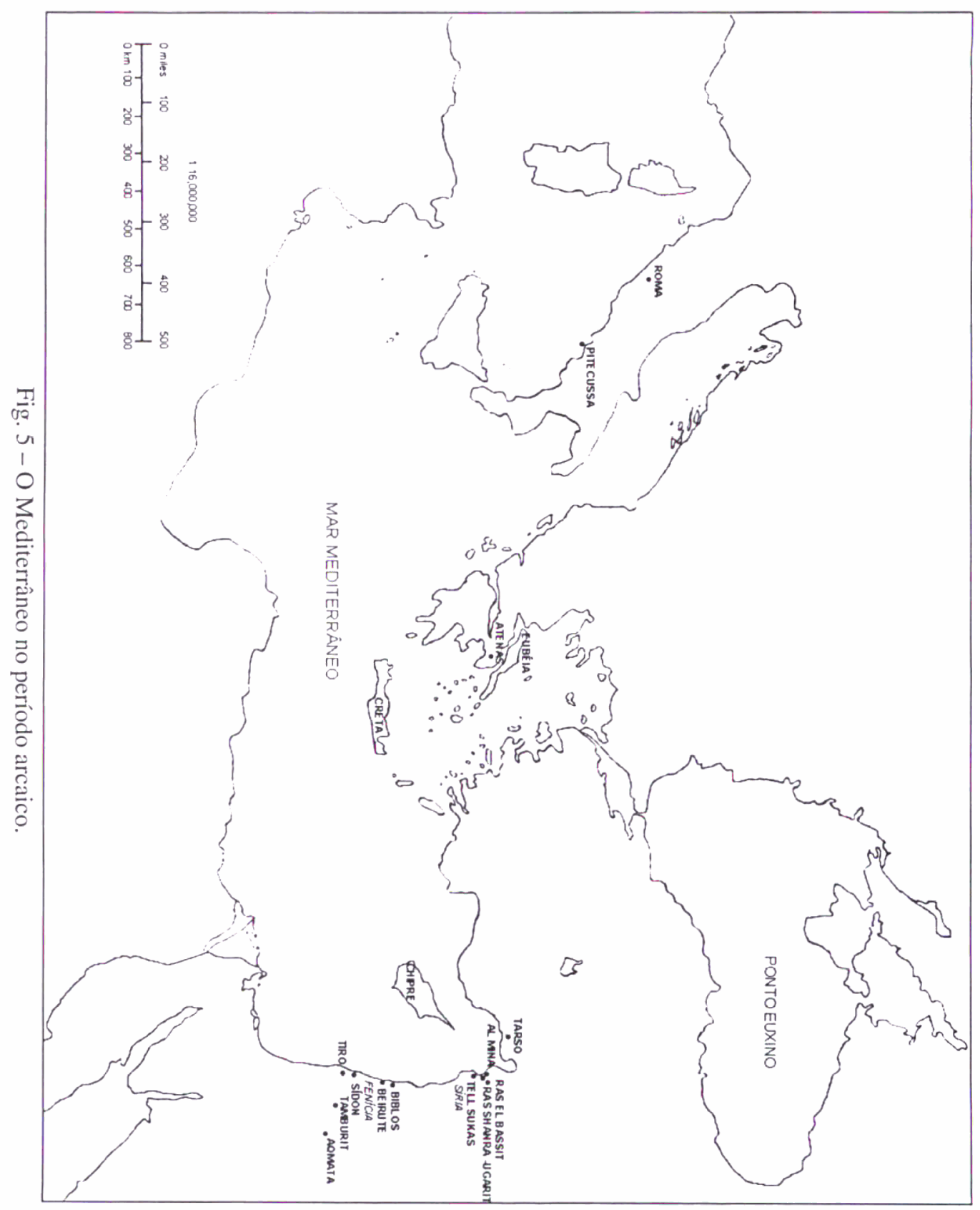



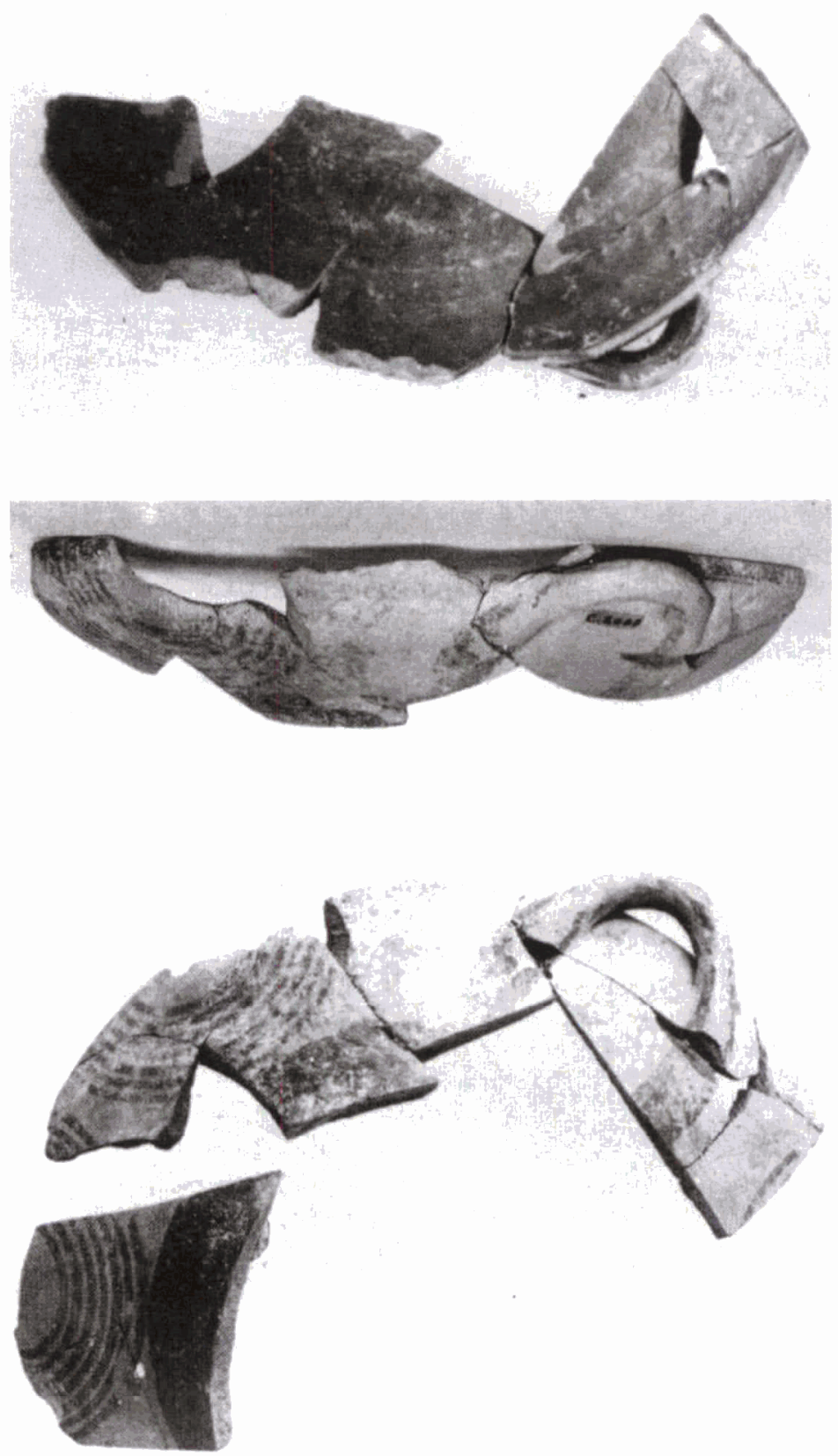

Fig. 6 - Fragmentos de taça cicládica Ras-el-Bassit. (Courbin, 1984, p. 196. fig. 3). 

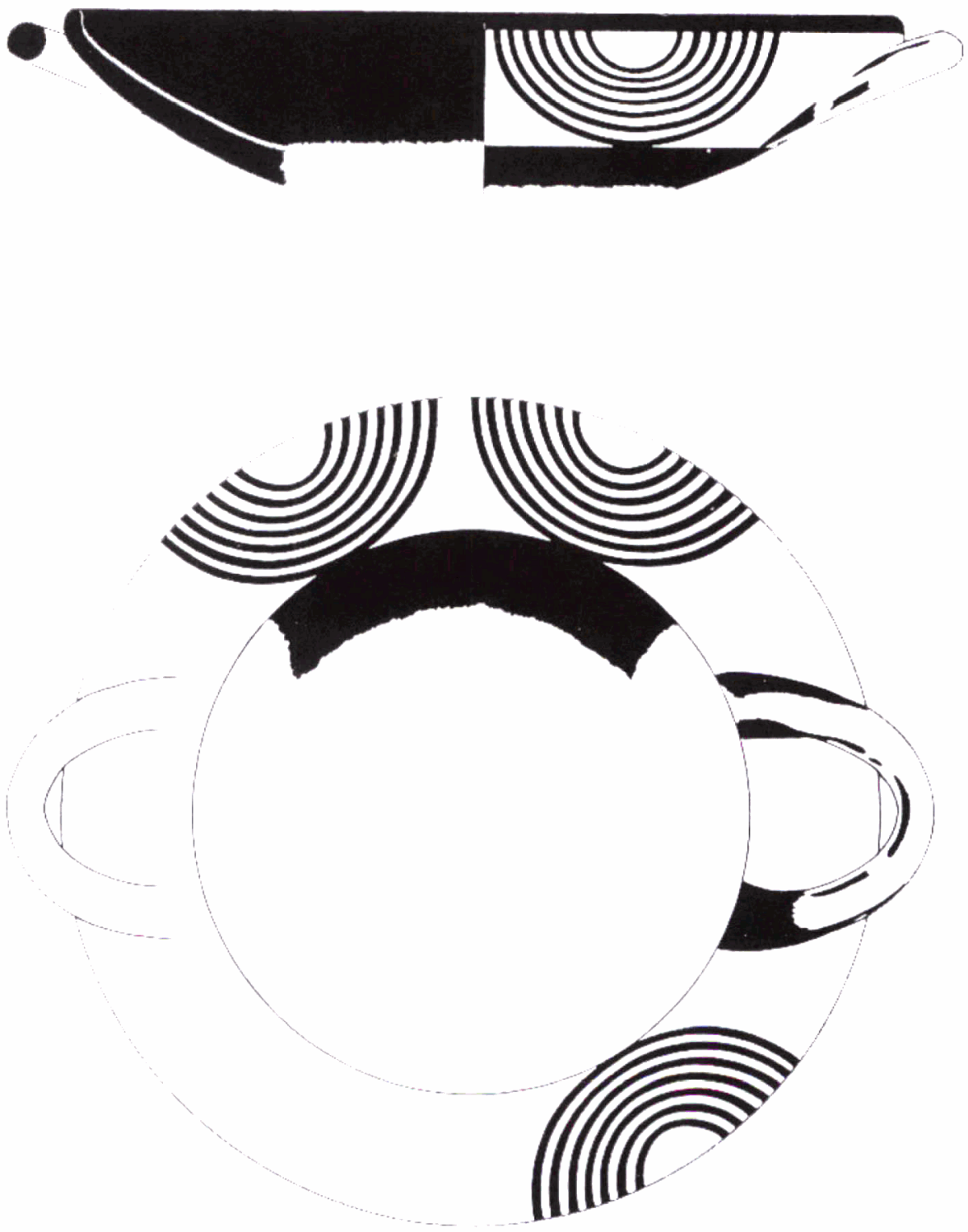

Fig. 7 - Desenho e reconstrução da fig. 6. (Courbin, 1984, p. 197, fig. 4). 


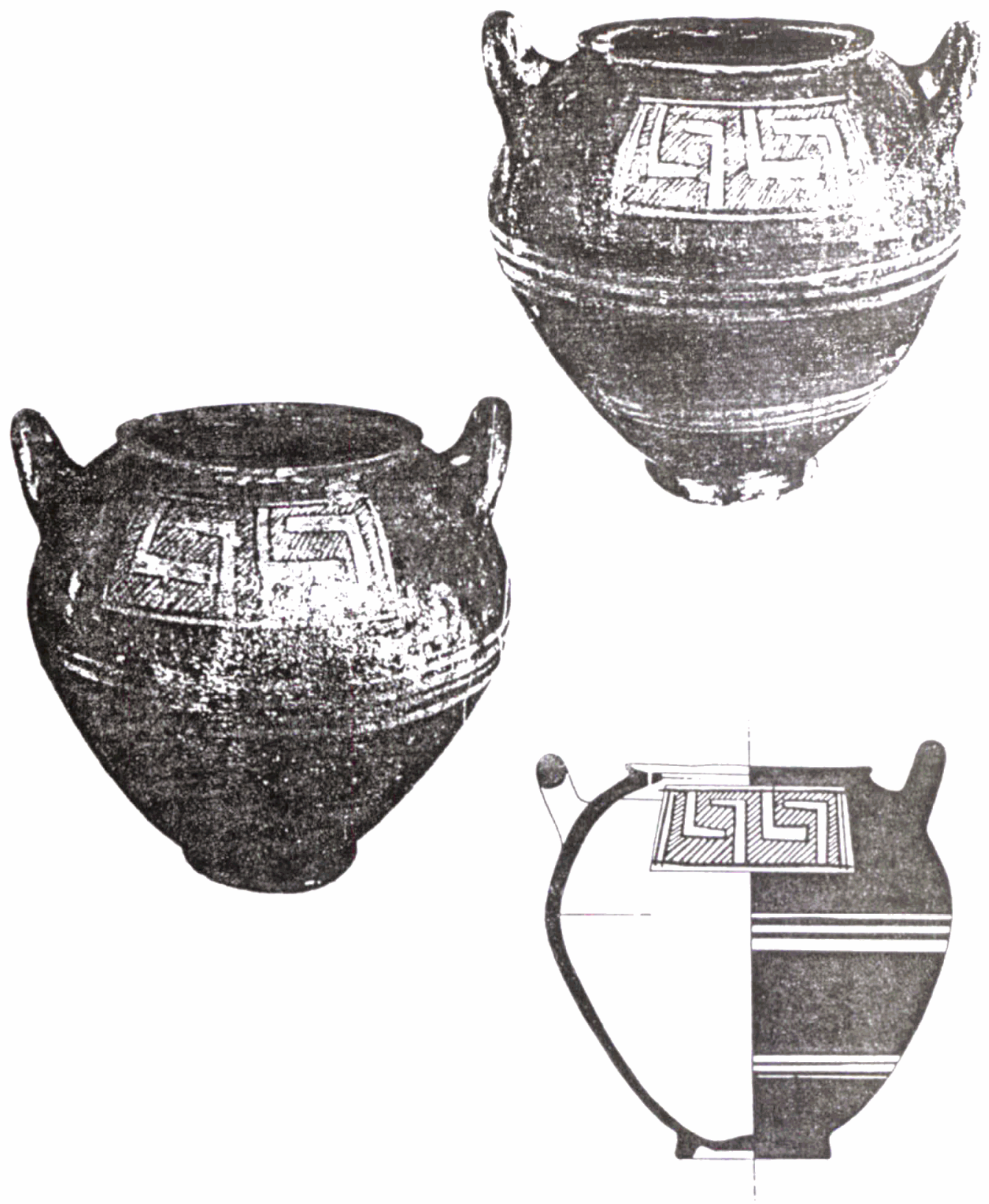

Fig. 8 - Píxide geométrica de Tamburit. (Courbin, in Saidah, 1977, p. 147-157). 

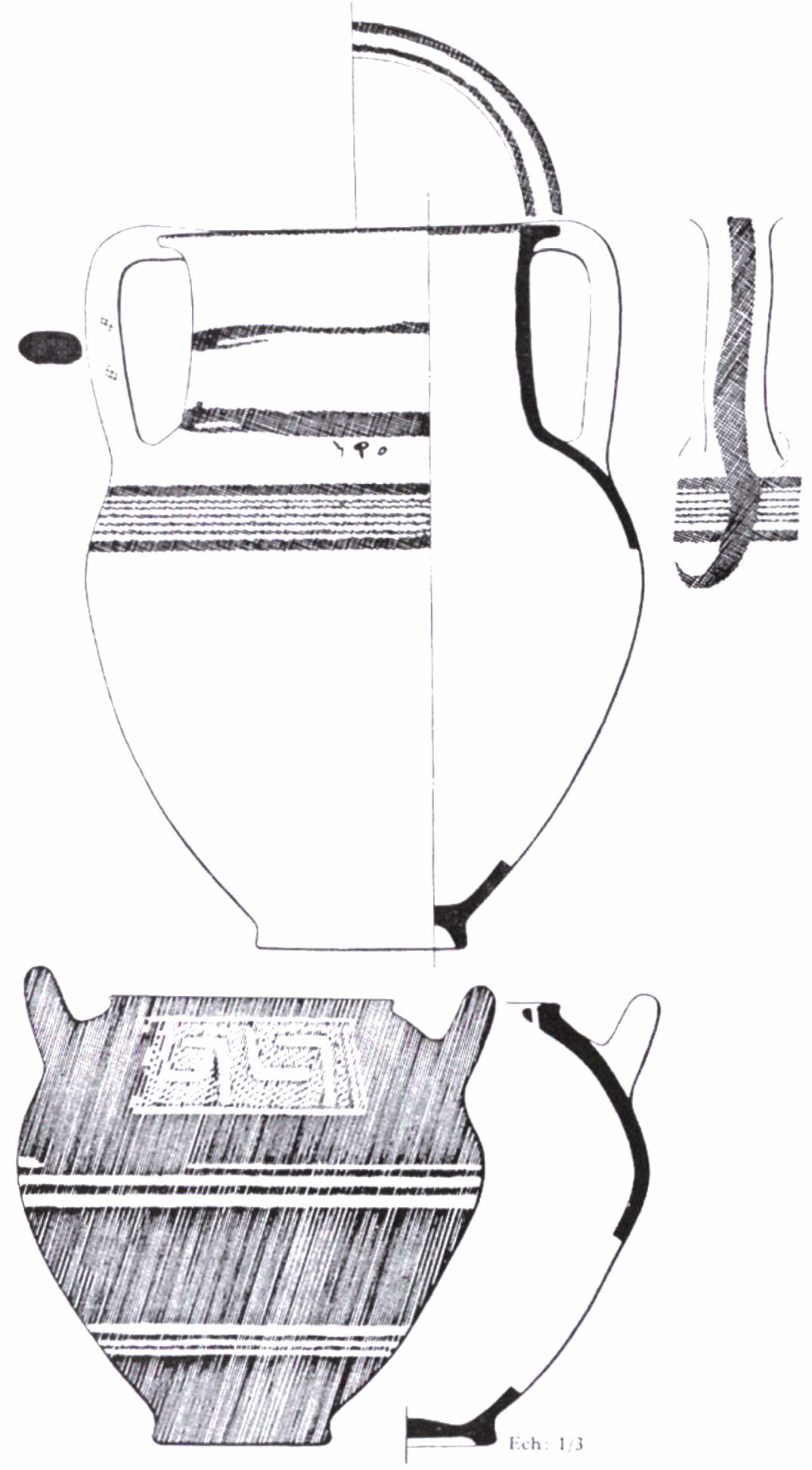

Fig. 9 - Ânfora com epígrafe fenícia. Tamburit. (Saidah, 1977, p. 141 e 145). 


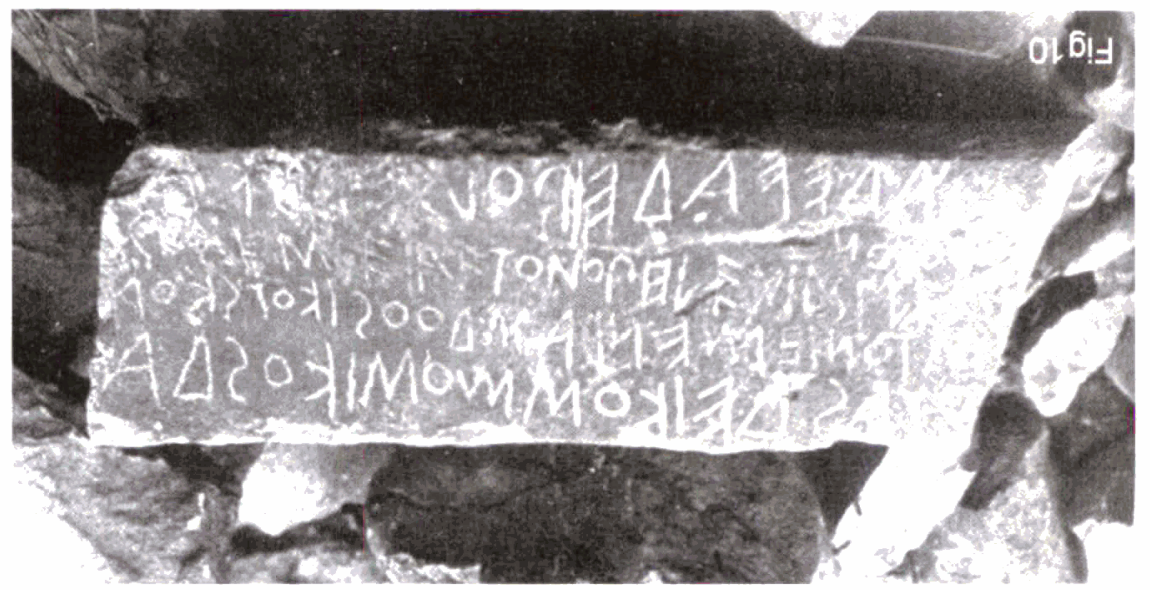

Fig. 4 - Inscrição latina de Osteria dell'Osa (necrópole de Gabies, tumba 115). (Collona, fig. I). 